\title{
Thickness Effect on the Formation of FePt Nanoparticles in FePt/C Multilayers
}

\author{
Y. Zhang*, J. Wan*, S. Stoyan*, V. Skumryev*, G. C. Hadjipanayis*, and D. Weller** \\ *Department of Physics \& Astronomy, University of Delaware, Newark, DE 19716, USA \\ ** Seagate Technology, Pittsburgh, PA 15203, USA
}

The as-deposited FePt thin films are in the form of fcc disordered A1 structure. The magnetically soft fcc structure will transform to the fct $\mathrm{L} 1_{0}$ structure after high temperature annealing, exhibiting a high magnetic anisotropy, which makes FePt thin films become one of best candidates for high density recording media [1-2]. The role of carbon in the disorder-order transformation of $\mathrm{FePt} / \mathrm{C}$ thin films has not been clear, although Carbon is used as a non-magnetic matrix to isolate the FePt nanoparticles in FePt/C thin films. This work is to study the effect of both carbon layer thickness and the repetition number on the microstructural evolution in $\mathrm{FePt} / \mathrm{C}$ thin films. The nanoparticles were formed by annealing multilayers of $\mathrm{FePt} / \mathrm{C}$ precursors at around $700^{\circ} \mathrm{C}$. The $\mathrm{FePt} / \mathrm{C}$ multilayered films were deposited by dc magnetron sputtering from solid FePt and Carbon targets onto Si (111) substrates using the tandem deposition technique. A $200 \AA$ layer of $\mathrm{C}$ was used as an underlayer and overlayer to encapsulate the $\mathrm{FePt} / \mathrm{C}(5 \AA / 5 \AA$ and $5 \AA / 20 \AA)$ multilayers (consisting of 3-100 repetitions) in order to reduce any effect from the substrate and to avoid oxidation during annealing. Cross-sectional and planar view TEM were carried out on JEOL JEM -2000FX and JEOL JEM-3010 to study the microstructure.

Figure 1 shows the microstructure in the $\mathrm{FePt} / \mathrm{C}$ (100 repetitions) samples with different carbon layer thickness. No layered structure was observed in the as-deposited $5 \AA / 5 \AA \mathrm{FePt} / \mathrm{C}$ sample (figure $1 \mathrm{a}$ ). Because the thickness of each deposited carbon layer is only $5 \AA$, the surface mobility during thin film growth is enough to break the layers in the as-deposited sample. This as-deposited sample consisted of a fine microstructure with a uniform narrow particle size distribution centered at $3 \mathrm{~nm}$. The degree of atomic ordering of the fct structure increases with annealing at $700^{\circ} \mathrm{C}$. After $1 \mathrm{hr}$ aging, the $5 \AA / 5 \AA$ sample shows the aggregation of particles up to $20 \mathrm{~nm}$ and a well-ordered fct structure (figure $1 \mathrm{~b}$ ). Similar microstructure is observed in the as-made $5 \AA / 20 \AA \mathrm{FePt} / \mathrm{C}$ sample, but the cross-sectional TEM shows the FePt/C layers (figure 1c). Cross-sectional TEM reveals the layers are completely broken after 5 min annealing. Both particle size and degree of atomic ordering increase very slowly with further annealing in the $5 \AA / 20 \AA$ sample. After $1 \mathrm{hr}$ annealing, an average particle size of $6 \mathrm{~nm}$ is observed, and only weakly intense (001) superlattice reflection is observed on the electron diffraction pattern (figure 1d). It means that there is a mixture of fcc and fct structures in this $5 \AA / 20 \AA$ sample. Both morphology and structure in the as-deposited $5 \AA / 5 \AA$ sample with 3 repetitions do not change, in comparison with the 100 repetitions sample. An isolated particle morphology is observed in the both planar and cross-sectional view TEM samples, even after annealed at $700^{\circ} \mathrm{C}$ for $1 \mathrm{hr}$, with $7 \mathrm{~nm}$ of mean particle size and a well-developed fct structure (figure 2). Elongated particles are observed in the cross-sectional TEM sample, which is believed to lead to magnetic anisotropy. Therefore, both carbon layer thickness and repetition number can strongly affect the phase transformation during annealing. The larger carbon layer thickness or fewer repetitions will lead to small and isolated particle morphology in the $\mathrm{FePt} / \mathrm{C}$ thin films [3].

References

[1] T. Hayashi, S. Hirono, M. Tomita, and S. Umemura, Nature (London) 381, 772 (1996). 
[2] J.-U. Thiele, L. Folks, M. F. Toney, and D. K. Weller, J. Appl. Phys. 84, 5686 (1998).

[3] This research was supported by the NSF under Grant No.DMR-9972035 and Seagate.
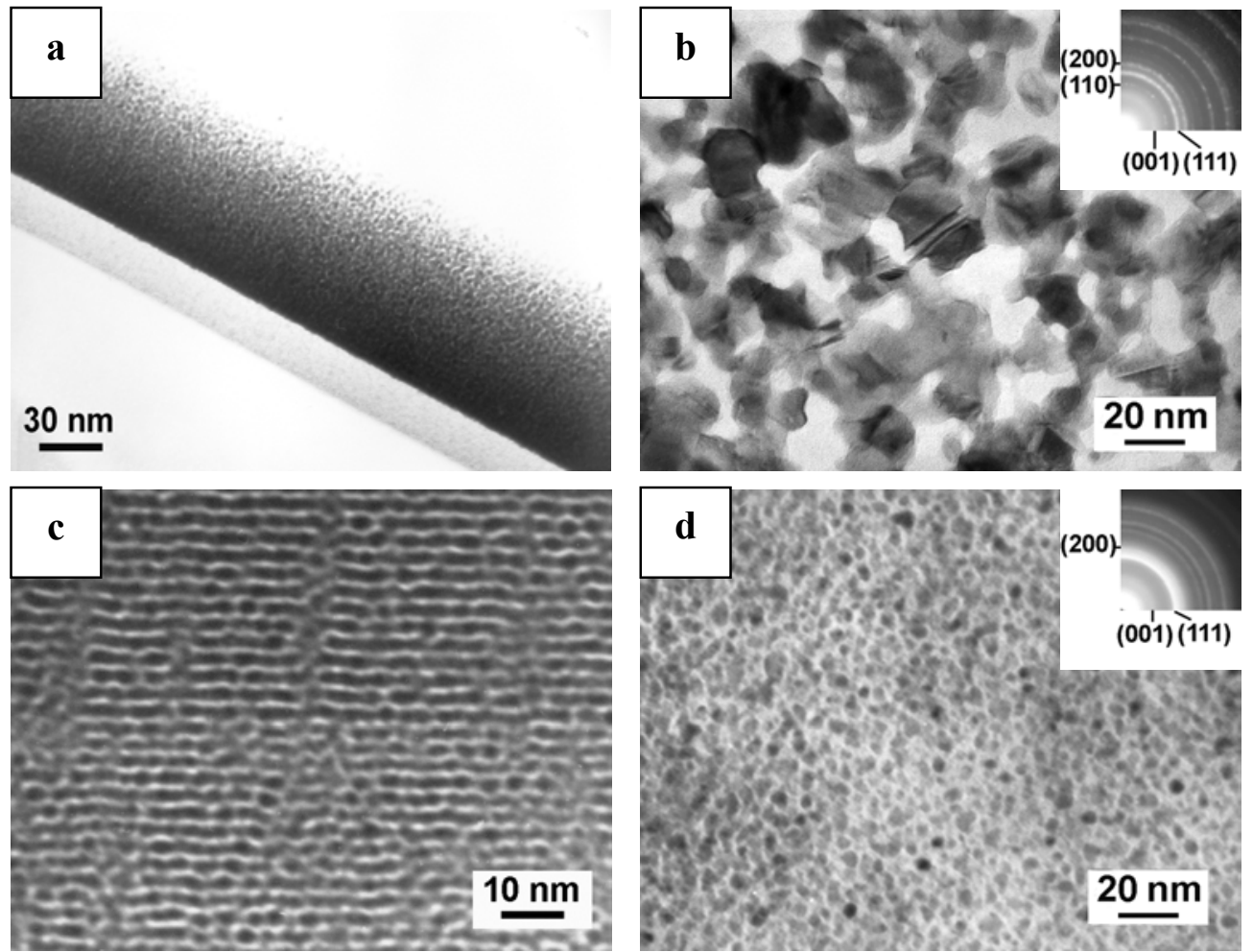

Figure 1 TEM microstructure of $5 \AA / 5 \AA$ and $5 \AA / 20 \AA \mathrm{FePt} / \mathrm{C}$ samples with 100 repetitions: (a) Crosssectional of the as-deposited $5 \AA / 5 \AA$ sample; (b) Planar view of the $5 \AA / 5 \AA$ sample annealed at $700^{\circ} \mathrm{C}$ for $1 \mathrm{hr}$, the insert EDP showing a well-ordered fct structure; (c) Cross-sectional of the as-deposited $5 \AA / 20 \AA$ sample; (d) Planar view of the $5 \AA / 20 \AA$ sample annealed at $700^{\circ} \mathrm{C}$ for $1 \mathrm{hr}$, and the insert EDP showing a mixture of fct plus fcc.
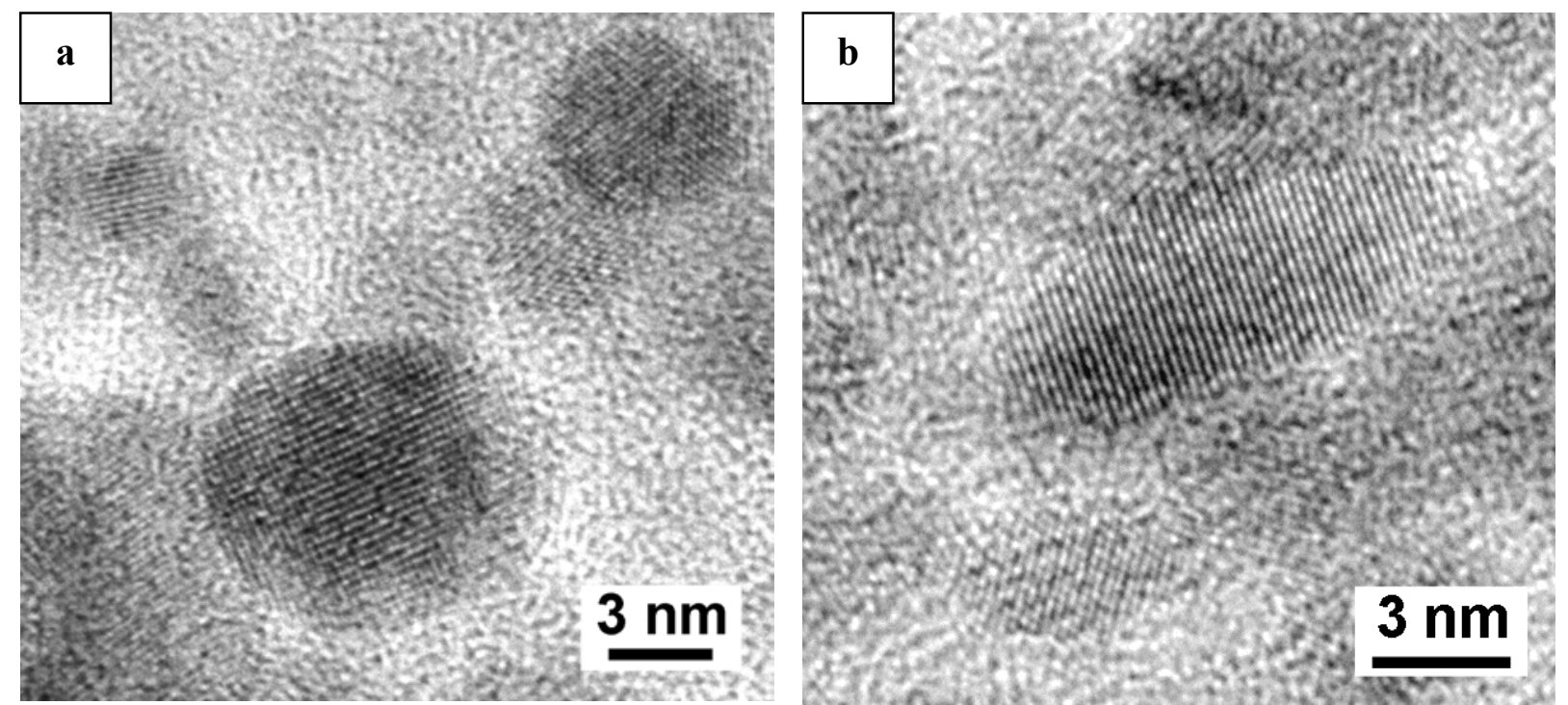

Figure 2 HREM of $5 \AA / 5 \AA \mathrm{FePt} / \mathrm{C}$ samples with 3 repetitions: (a) Planar view; (b) Cross-sectional. 